\title{
Daily and seasonal thermal energy storage for enhanced flexible operation of low-temperature heating and cooling network
}

\author{
Andrea Vecchi ${ }^{a}$, Behzad Rismanchi ${ }^{b}$, Pierluigi Mancarella ${ }^{c}$ and Adriano Sciacovelli \\ a University of Birmingham, Birmingham, UK, axv863@student.bham.ac.uk (CA) \\ ${ }^{b}$ The University of Melbourne, Melbourne, Australia, behzad.rismanchi@unimelb.edu.au \\ c The University of Melbourne, Melbourne, Australia, pierluigi.mancarella@unimelb.edu.au \\ d University of Birmingham, Birmingham, UK, a.sciacovelli@bham.ac.uk
}

\begin{abstract}
:
Synergic operation of electricity, heating and cooling networks can bring savings and low carbon footprint through energy efficiency. In such context, the present work proposes a novel Smart Thermal Loop (STL) solution: a fully electrified thermal generation and distribution system where a low-temperature underground loop and reversible heat pumps are used to supply users' heating and cooling demand. Additionally, STL includes short and long-term thermal energy storage (TES) by means of sensible storage tanks and geothermal boreholes. The proposed solution is described and investigated in the case of the new campus of the University of Melbourne (with aggregated peak load of about 2 and $3 \mathrm{MW}_{\text {th }}$, respectively, for heating and cooling). A numerical model is proposed to simulate the yearly operation of STL with 1-hour resolution. Key features include (i) network model for the underground loop to track temperature evolution over space and time, (ii) variable heat pump performance, which depends on network temperatures, (iii) physical model for the heat transfer between system and soil, in the geothermal storage, (iv) modelling of the interaction between neighbouring boreholes. Results explore the dynamics of the integrated STL system, with a focus on the role that energy storage over different timescales plays in enabling efficient and flexible operation of system components. TES contribution to system operation goes beyond the use of low-price electricity and allows energy savings through efficient scheduling of heat pumps operation and reduction of pumping work. Benefits from the flexible operation of STL are quantified as a $10 \%$ reduction in energy expenditure and $28 \%$ in system running costs. The presented model can also instruct on the impact of different design choices on STL operation.
\end{abstract}

\section{Keywords:}

$5^{\text {th }}$ generation district heating and cooling; Low temperature thermal network; MILP optimisation; Geothermal storage; Thermal energy storage.

\section{Introduction}

Building sector accounts for $32 \%$ of the global final energy demand and $30 \%$ of the associated carbon emissions. $50-60 \%$ of such demand is due to thermal uses [1], which highlights efficient provision of heating and cooling as vital to any energy decarbonisation endeavours. Rising projections for building thermal use, mostly driven by cold [2], and increased urbanisation levels will lead to higher and more localised thermal demand [3]. In this context, District Energy Networks (DEN) offer a valuable way forward through the implementation of energy conservation and efficiency measures [4], as well as the design and operational flexibility to be effectively integrated with the electricity sector [5].

Latest research on DEN is now focussing on the so-called $5^{\text {th }}$ generation district heating and cooling (5GDHC) networks. These are defined as "thermal energy supply grids that use water or brine as a carrier medium and hybrid substations with water source heat pumps. [...] The possibility to reverse operation of the customer substations permits to cover simultaneously and with the same pipelines both the heating and cooling demands of different buildings" [6]. 5GDHC networks leverage the smart operation of well-proven technologies to foster technical, economic and environmental benefits [7]. Low network temperatures enable the reduction of thermal losses [8], integration of low-enthalpy renewable sources and waste heat [9] and the achievement of high performance values for the ground-source heat pumps [10]. Also, seasonal storage is an integral part of $5 \mathrm{GDHC}$ systems [11]. Given such desirable features, a number of projects are currently delving into specific 
aspects of $5 \mathrm{GDHC}$ network deployment and about 40 demonstration sites have been so far operated in Europe, at different scales [6].

Despite the interest in real-life implementations, literature focussing on 5GDHC has only recently gathered momentum, with most works focussing on network operation and simulation. Indeed, advanced system control is key to unlock flexibility, but challenges come from the complex dynamics which is specific to 5GDHC networks [12]. An agent-based control was proposed to optimise the temperature of two bidirectional networks [13], showing $13 \%$ and $41 \%$ electricity use reduction compared to free-floating temperature approach. Model predictive control and recurrent artificial neural network were used for smart control of user substations [14]. Wirtz et al. and Gabrielli et al. considered a 2-pipe layout and showed how an optimally operated 5GDHC system can bring $42 \%$ cost reduction [15] and up to $87 \% \mathrm{CO}_{2}$ reduction [16]; they both relied on a limited number of reference days. Hourly simulations were carried out for a single-pipe network [17], but without discussing the technical operation for the system, nor its interaction with seasonal storage. Other works optimised system operation assuming constant network temperatures [18] or fixed performance of the heat pumps [19]. Ultimately, the reviewed literature on 5GDHC networks shows highly case-dependent results, which calls for more cases with different network layouts, climate zones and demand profiles to be investigated, and focus on system-level benefits with little discussion of the interaction between 5GDHC network subsystems.

In this study, we aim at tackling the lack of technical description of specific 5GDHC network subsystems and their interaction, during operation, as well as the missing assessment of 5GDHC solutions for climate conditions other than the typical European cases with prevailing heating demand. We focus our attention on the value that thermal energy storage (TES) over different timescales (daily and seasonal) has in determining efficient and economical network operation of a proposed smart thermal loop (STL) system: a fully electrified, single-loop 5GDHC network where reversible heat pumps supply users' heating and cooling demand. Additionally, we discuss how different TES design choices affect such roles. The proposed STL for the new UoM campus in Melbourne, Australia is taken as a case study.

The assessment is based on a simulation tool developed to capture system dynamics through: i) a network model for the low-temperature underground loop, ii) variable heat pump performance based on network temperatures and iii) a physical model for heat transfer in the seasonal storage, capturing the transient heat conduction to and from the soil. Results can inform on the role of TES, advance the technical understanding of 5GDHC network operation and suggest appropriate system and TES design. The present study can contribute to the development and application of $5 \mathrm{GDHC}$ networks, especially in the Australian context.

\section{Overview of the STL system}

Fig. 1 illustrates a schematic of the STL system, whose modelling is described in section 3. A hybrid solution with water source heat pumps and a cooling tower was considered, as detailed in section 4 .

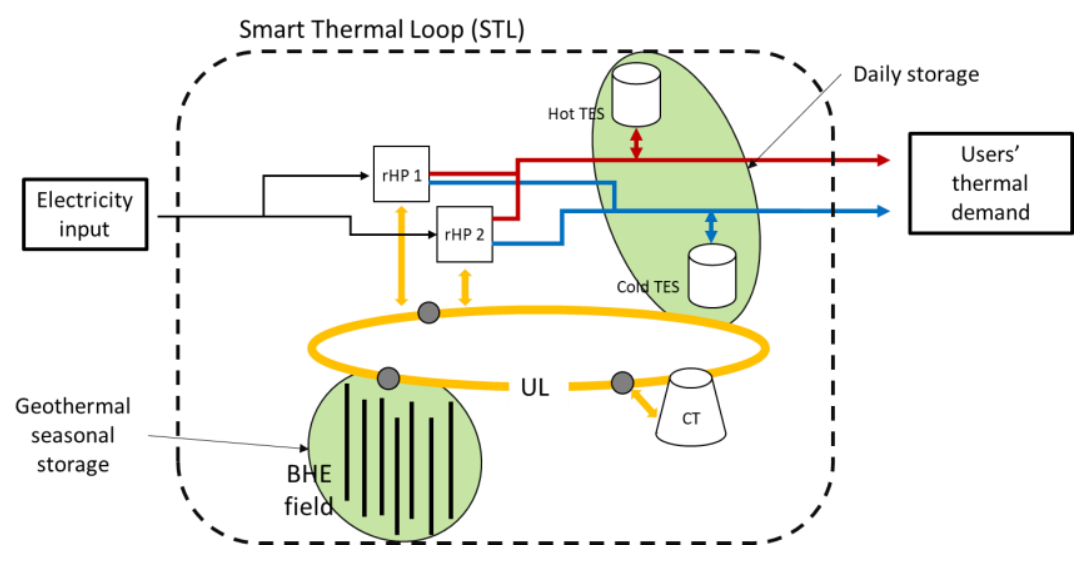

Fig. 1. STL system layout and modelling details.

Users' thermal demand is supplied by a set of reversible heat pumps (rHP). These devices can be operated alternatively in heating or cooling mode, simply by switching the internal refrigerant flow through a 4-way valve or an equivalent device. An underground water/glycol loop (UL) acts as a source (or sink) for the rHP during heating (cooling) provision. Although several network layouts are possible for the UL, the investigated solution involves a single-loop layout - sometimes referred to as reservoir network - which can have comparable energy expenditure to 2-pipes, bidirectional networks, yet with a simpler design [17]. Geothermal heat transfer through a borehole heat exchanger (BHE) field serves seasonal storage purposes. It allows to store heat surplus during periods of high cooling load and to retrieve it when heating demand is predominant. Additionally, 
an atmospheric cooling tower (CT) is included in the layout to reject excessive heat towards the atmosphere when ambient temperature is below the local values in the UL.

\section{Methodology}

The model is a 24-h rolling horizon optimisation with hourly resolution. Note that, for clarity, decision variables in the model are highlighted by bold-faced characters, hereafter, while model parameters are formally defined in Table 2, when not explicitly presented elsewhere.

\subsection{Objective function}

To address system operation, a simulation tool for STL was developed in this study. It is based on mixed integer linear programming (MILP) technique and seeks to minimise system running costs, as expressed by Eq. (1), in terms of electricity input to the rHP (term 1) and pumping work (term 2).

$\min \sum_{t=1}^{T} \pi_{t}\{\underbrace{\sum_{i=1}^{I} \boldsymbol{P}_{i, t}^{r H P}}_{1}+\underbrace{\frac{1}{\eta_{P}}\left[\boldsymbol{y}_{\boldsymbol{t}}^{\boldsymbol{P}}\left(\frac{\dot{m}_{U L} \Delta p_{U L}}{\rho}+\frac{N_{B H E} \dot{m}_{B H E} \Delta p_{B H E}}{\rho}\right)+\sum_{i=1}^{I} \boldsymbol{y}_{\boldsymbol{i}, t}^{r \boldsymbol{H} P} \frac{\dot{m}_{r H P} \Delta p_{r H P}}{\rho}+\boldsymbol{y}_{\boldsymbol{t}}^{C T} \frac{\dot{m}_{U L} \Delta p_{C T}}{\rho}\right]}_{2}\} \Delta t$

Electricity is purchased from the grid at the spot market price, $\pi_{t}$, whereas both distributed and localised pressure losses are accounted in the pumping work, based on the on/off status of STL subsystems, $\boldsymbol{y}_{\boldsymbol{t}}$. The detailed technical model formulation for selected system components is described in the next section.

\subsection{Detailed model formulation of selected components}

\subsubsection{Piping network}

A transient energy balance was imposed at each node $n$ of the UL, to keep track of temperature evolution along the network as shown in Eq. (2). Equations were discretized in time using a backwards Euler scheme and include heat injection/rejection terms, $\mathbf{Q}_{n, t}$, to model the thermal interaction with conversion and storage technologies. Along the piping, thermal losses towards the soil were neglected due to the low network temperatures [16], while distributed losses were accounted using the Petukhov correlation and a 1D pipe model [20].

$\rho c_{p} \frac{V_{U L}}{N}\left(\frac{T_{n, t}^{U L}-\boldsymbol{T}_{n, t-1}^{U L}}{\Delta t}\right)+\dot{m}_{U L} c_{p}\left(\boldsymbol{T}_{n, t}^{U L}-\boldsymbol{T}_{n-1, t}^{U L}\right)=\mathbf{Q}_{n, t}$

\subsubsection{Reversible heat pumps}

Equation (3) and Eq. (4) ensured that the rHP were operated within their maximum capacity, as well as making sure only heating or cooling was provided at each point in time, by introducing the binary variable $z_{i, t}^{r H P}$. Another binary variable, $\boldsymbol{y}_{i, t}^{r H P}$, was introduced and used in Eq. (5) to track the on/off status of each rHP.

$\boldsymbol{Q}_{\boldsymbol{i}, \boldsymbol{t}}^{r \boldsymbol{r} \boldsymbol{P} \boldsymbol{H}} \leq \overline{Q^{r H P, H}} \boldsymbol{z}_{\boldsymbol{i}, \boldsymbol{t}}^{r \boldsymbol{P}}$

$\boldsymbol{Q}_{i, t}^{r H P, C} \leq \overline{Q^{r H P, C}}\left(1-\boldsymbol{z}_{i, t}^{r H P}\right)$

$\boldsymbol{Q}_{i, t}^{r H P, \boldsymbol{H}}+\boldsymbol{Q}_{i, \boldsymbol{t}}^{r H P, \boldsymbol{C}} \leq \boldsymbol{y}_{\boldsymbol{i}, \boldsymbol{t}}^{r H P} \operatorname{Max}\left(\overline{Q^{r H P, H}} ; \overline{Q^{r H P, C}}\right)$

In a 5GDHC network, where the source/sink for rHP is provided by UL, it was crucial to include rHP performance variation based on the local network temperatures. A stepwise formulation was used to track coefficient of performance (COP) and energy efficiency ratio (EER) evolution and retain model linearity at the same time. This was attained through Eq. (6)-(9), where $M$ is a big-enough number, $\underline{T}_{s}, \bar{T}_{s}, C O P_{S}$ and $E E R_{S}$ represents, respectively, the lower and upper temperature limit, the COP and EER value of each step.

$\sum_{s \in \mathbf{S}} \boldsymbol{u}_{\boldsymbol{s}, \boldsymbol{t}} \underline{T}_{S} \leq \boldsymbol{T}_{\mathbf{3}, t}^{\boldsymbol{L}} \leq \sum_{s \in \boldsymbol{S}} \boldsymbol{u}_{\boldsymbol{s}, \boldsymbol{t}} \bar{T}_{s}$

$\sum_{s \in S} \boldsymbol{u}_{s, t}=1$

$\boldsymbol{P}_{i, t}^{r H P}+M \geq \frac{Q_{i, t}^{r P P, H}}{C O P_{S}}+\frac{\boldsymbol{Q}_{i, t}^{r H P, C}}{E E R_{S}}+\boldsymbol{u}_{s, t} M$ 
$\boldsymbol{P}_{i, t}^{r H P}-M \leq \frac{Q_{i, t}^{r H P, H}}{C O P_{S}}+\frac{Q_{i, t}^{r H P, C}}{E E R_{S}}-\boldsymbol{u}_{s, t} M$

\subsubsection{Geothermal heat transfer and BHE field}

A linear model including the heat transfer physics between soil and BHE was chosen, which uses $g$-functions to describe the soil temperature evolution in space and time, based on the exchanged heat flux, the BHE field geometry and soil diffusive properties. We implemented the analytical expression of the g-function from [21] and function convolution over time (Eq. (10)) to compute the soil response to variable heat pulses [22]. The heat transferred from each $\mathrm{BHE}$ was finally computed by knowing the equivalent thermal resistance of the borehole, $R_{B H E}$, the flow rate through the BHE, $\dot{m}_{B H E}$, and the UL temperature at the inlet of the BHE field.

$\boldsymbol{T}_{\boldsymbol{t}}^{\boldsymbol{B} H \boldsymbol{E}}=T_{\infty}-\sum_{t^{*}=1}^{t} \frac{\left(\boldsymbol{Q}_{t^{*}}^{B H E}-Q_{t^{*}-1}^{B H E}\right)}{2 \pi k L} \tilde{g}\left(\frac{t-\left(t^{*}-1\right)}{\tau_{S S}}, \frac{r_{b}}{L}\right)$

$\frac{T_{2, t}^{U L}+T_{t}^{o u t}}{2}=T_{t}^{B H E}-\frac{Q_{t}^{B H E} R_{B H E}}{L}$

$Q_{t}^{B H E}=\dot{m}_{B H E} c_{p}\left(\boldsymbol{T}_{t}^{o u t}-T_{2, t}^{U L}\right)$

The thermal interaction was accounted through Eq. (13), where $\tilde{g}$ describes the average response of the whole field, including spatial superposition of all the boreholes located within a cut-off region, each with its respective distance $r_{x y}$ from the $\mathrm{BHE} x$.

$\tilde{g}=\frac{1}{N_{B H E}} \sum_{x=1}^{N_{B H E}} g_{x}=\frac{1}{N_{B H E}} \sum_{x=1}^{N_{B H E}} g\left(\frac{t}{\tau_{s S}}, \frac{r_{b}}{L}\right)+\sum_{\forall y \neq x} g\left(\frac{t}{\tau_{s S}}, \frac{r_{x y}}{L}\right)$

This part of the model has been validated against the data from [23], which refer to a 2 X 2 BHE field, as highlighted in Fig. 2.

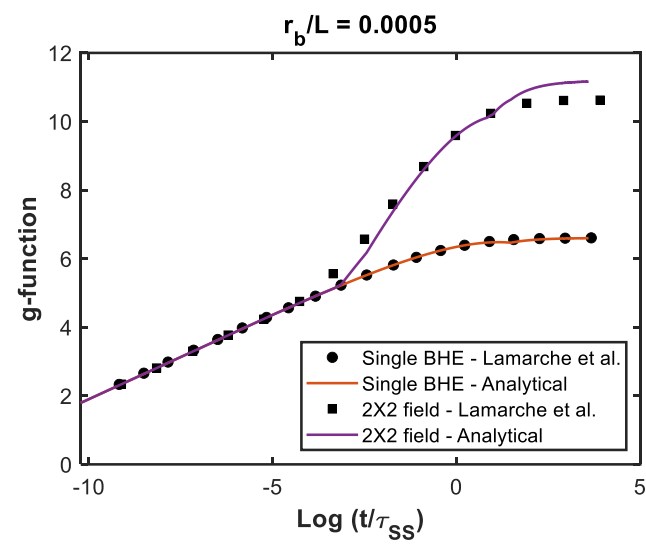

Fig. 2. Validation of the BHE field model against data from [23].

\subsubsection{Cooling tower}

The atmospheric cooling tower was modelled by Eq. (14)-(15), where heat rejection towards the environment is possible each time the temperature difference between UL and the ambient, $T_{A m b, t}$, is above a threshold $\Delta T^{C T}$. Both the CT size and the variable temperature difference between the underground loop and the ambient restrict the rejection capacity in Eq. (16)

$\Delta T^{C T}-\left(1-\boldsymbol{y}_{\boldsymbol{t}}^{C \boldsymbol{T}}\right) M \leq \boldsymbol{T}_{\mathbf{1}, \boldsymbol{t}}^{U \boldsymbol{L}}-T_{A m b, t}$

$-y_{t}^{C T} \overline{Q^{C T}} \leq Q_{t}^{C T} \leq 0$

$-\left(1-\boldsymbol{y}_{\boldsymbol{t}}^{C \boldsymbol{T}}\right) M \leq \boldsymbol{Q}_{\boldsymbol{t}}^{C \boldsymbol{T}}+\dot{m}_{U L} c_{p}\left[\boldsymbol{T}_{\mathbf{1 , t}}^{U L}-\left(T_{A m b, t}+\Delta T^{C T}\right)\right]$

\subsubsection{Thermal energy storage}

Bot hot and cold TES were modelled following the typical battery-like model from the literature (Eq. (17)), with the inclusion of charging and discharging efficiency and self-discharge losses proportional to the stored energy.

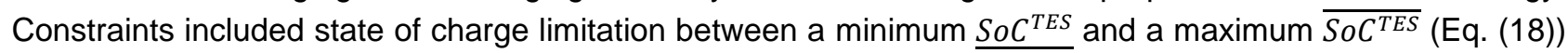
and the maximum charge and discharge power, constrained by the TES design, according to Eq. (19)-(20). 
$\operatorname{SoC}_{j, t}^{T E S}=\operatorname{SoC}_{j, t-1}^{T E S}(1-\Lambda \Delta t)+\left(\eta_{T E S} Q_{j, t}^{T E S, i n}-\frac{1}{\eta_{T E S}} \boldsymbol{Q}_{j, t}^{T E S, o u t}\right) \Delta t$

$\underline{S o C^{T E S}} \leq \operatorname{SoC}_{j, t}^{T E S} \leq \overline{S o C^{T E S}}$

$Q_{j, t}^{T E S, \text { in }} \leq \boldsymbol{y}_{j, t}^{T E S} \frac{\overline{\operatorname{SoC}^{T E S}}}{\tau}$

$\boldsymbol{Q}_{j, t}^{T E S, o u t} \leq\left(1-\boldsymbol{y}_{j, t}^{T E S}\right) \overline{\frac{\operatorname{SoC^{TES}}}{\tau}}$

\subsection{Supply-demand balancing}

To express the constant matching between supply and demand for heat $\left(D_{t}^{H}\right)$ and cold $\left(D_{t}^{C}\right)$ by the users, Eq. (21) and Eq. (22) were imposed, respectively, as additional constraints to STL operation.

$\sum_{i=1}^{I} \boldsymbol{Q}_{i, t}^{r H P, H}+\sum_{j}\left(\boldsymbol{Q}_{j, t}^{T E S, o u t}-\boldsymbol{Q}_{j, t}^{\boldsymbol{T E S}, \text { in }}\right)=\left|D_{t}^{H}\right| \quad j \in J^{H}$

$\sum_{i=1}^{I} \boldsymbol{Q}_{i, t}^{r H P, C}+\sum_{j}\left(\boldsymbol{Q}_{j, t}^{T E S, o u t}-\boldsymbol{Q}_{j, t}^{T E S, \text { in }}\right)=\left|D_{t}^{C}\right| \quad j \in J^{C}$

\section{Case study description}

The developed model was used to simulate the yearly operation of the new University of Melbourne campus at Fishermans Bend (FB), which comprises of 5 multi-purpose buildings to be served, adding up to $42000 \mathrm{~m}^{2}$ total lettable area. Thermal load profiles were evaluated by the design team, based on the historical consumption data from analogous building archetypes in the present campus. Aggregated values with hourly resolution are shown in Fig. 3 and have been used as input to the analysis; they display hourly, weekly and seasonal patterns. Specifically, heating is required throughout the year, although in very low amounts in summer. The maximum heating load is $1.75 \mathrm{MW}$ and the yearly consumption $500 \mathrm{MWh}$; the maximum-toaverage ratio is 31.25. For cooling, the maximum load is $2.9 \mathrm{MW}$, yearly consumption $1400 \mathrm{MWh}$ and maximum-to-average ratio 18.3. Overall, the system is cooling dominated, with 3 times higher cooling needs and imbalanced thermal demand.

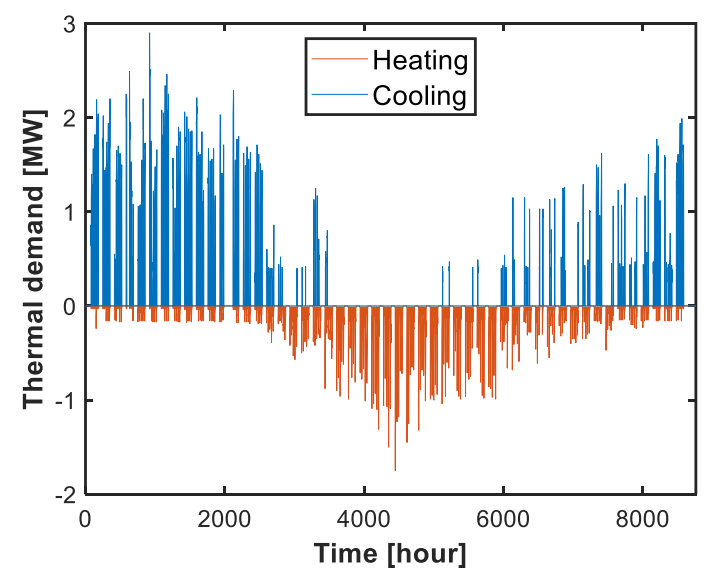

Fig. 3. Yearly heating and cooling demand profiles for the FB campus, with hourly resolution.

\subsection{STL design and model parameters}

A hybrid layout was chosen as a cost-effective practice in the case of predominant cooling load [24]. As the focus here is operational, a number of preliminary assumptions were made regarding the sizing of individual system components. These mainly related to: i) the geothermal storage system, described by the number of $\mathrm{BHE}, N_{B H E}$, and their length, ii) the UL design in terms of piping diameter, overall fluid volume, $V_{U L}$, and circulation flow rate and iii) the CT and its thermal rejection capacity, $\overline{Q^{C T}}$. We used reported data for similar systems in the literature [25] to fix the values of the key design parameters, as described in Table 1. Regarding the hot and cold TES, different sizes and the associated effect on system operation have been explored, as detailed in section 5.2.1. 
Table 1. Selected values of STL design parameters.

\begin{tabular}{cll}
\hline $\begin{array}{l}\text { Design } \\
\text { parameter }\end{array}$ & Value & Notes \\
\hline$N_{B H E}$ & 300 & Assumed $65 \mathrm{~W} / \mathrm{m}$ BHE yield and $150 \mathrm{~m}$-long boreholes \\
$V_{U L}$ & $200 \mathrm{~m}^{3}$ & Assumed $50 \mathrm{~cm}$ piping diameter, and $\sim 2 \mathrm{~m} / \mathrm{s}$ circulation speed for $1 \mathrm{~km}$-long UL \\
$Q^{C T}$ & $500 \mathrm{~kW}$ & Follows the design procedure proposed in [24] \\
\hline
\end{tabular}

Model input parameters and timeseries are gathered in Table 2. The performance modelling for the heat pumps was tackled by the Carnot coefficient approach [17], where COP $=\phi^{H}\left(\frac{T_{\text {cond }}}{T_{\text {cond }}-T_{\text {eva }}}\right)$ and $E E R=\phi^{C}\left(\frac{T_{\text {eva }}}{T_{\text {cond }}-T_{\text {eva }}}\right)$, for heating and cooling mode, respectively. Heat generation temperatures of 50 and $2{ }^{\circ} \mathrm{C}$ were considered, to ensure 45 and $7{ }^{\circ} \mathrm{C}$ supply, and the reported data for the reversible VITOCAL 350G model from Viessman [26] were fitted to obtain the coefficients $\phi^{C}$ and $\phi^{H}$ from the manufacturer datasheet. Diffusive soil properties were evaluated onsite, through a thermal response test and have been used for model setup.

Table 2. Definition and values of relevant parameters for model setup.

\begin{tabular}{|c|c|c|c|}
\hline Parameter & Definition & Value & Notes \\
\hline \multicolumn{4}{|c|}{ System devices } \\
\hline$\phi^{H}$ & Carnot coefficient - heating & 0.535 & From manufacturer datasheet \\
\hline$\phi^{C}$ & Carnot coefficient - cooling & 0.502 & From manufacturer datasheet \\
\hline$\overline{Q^{r H P, \mathrm{H}}}$ & Heat pump capacity - heating & $2.7 \mathrm{MW}$ & $50 \%$ oversizing on heating peak \\
\hline$\overline{Q^{r H P, C}}$ & Heat pump capacity - cooling & $5.8 \mathrm{MW}$ & Based on rated values of $C O P$ \\
\hline$\eta_{T E S}$ & TES charge/discharge efficiency & 0.98 & \\
\hline$\Lambda$ & TES standing loss coefficient & $0.011 / \mathrm{h}$ & \\
\hline$\tau$ & Rated TES discharge time & $3 \mathrm{~h}$ & From reference [16] \\
\hline$\Delta T^{C T}$ & Cooling tower switch on threshold & $2^{\circ} \mathrm{C}$ & \\
\hline \multicolumn{4}{|c|}{ Geothermal heat exchange and UL } \\
\hline$T_{\infty}$ & Undisturbed soil temperature & $15^{\circ} \mathrm{C}$ & \\
\hline$r_{b}$ & Borehole radius & $0.0675 \mathrm{~m}$ & $125 \mathrm{~mm}$ BHE diameter \\
\hline$R_{B H E}$ & Borehole thermal resistance & $0.11 \mathrm{mK} / \mathrm{W}$ & Single U-tube with grouting [27] \\
\hline$\dot{m}_{B H E}$ & Borehole mass flow rate & $0.5 \mathrm{~kg} / \mathrm{s}$ & Fluid velocity is $0.38 \mathrm{~m} / \mathrm{s}$ \\
\hline$N$ & Network nodes & 3 & Total number of network nodes \\
\hline$L$ & Borehole length & $150 \mathrm{~m}$ & \\
\hline$c_{p}$ & Fluid specific heat capacity & 3.8 kJ/kgK & $30 \%$ ethylene glycol/water mix \\
\hline$\rho$ & Fluid density & $1046 \mathrm{~kg} / \mathrm{m}^{3}$ & $30 \%$ ethylene glycol/water mix \\
\hline \multicolumn{4}{|c|}{ Pressure losses and pumping work } \\
\hline$\Delta p_{B H E}$ & Pressure drop at boreholes & $25 \mathrm{kPa}$ & $35 \mathrm{kPa}$ for $250 \mathrm{~m}$ boreholes [17] \\
\hline$\Delta p_{r H P}$ & Pressure drop at heat pumps & $30 \mathrm{kPa}$ & ASHRAE guidelines below $35 \mathrm{kPa}$ \\
\hline$\Delta p_{C T}$ & Pressure drop at cooling tower & $40 \mathrm{kPa}$ & \\
\hline$\dot{m}_{r H P}$ & Heat pump flow rate & $200 \mathrm{~kg} / \mathrm{s}$ & Half of $\dot{m}_{U L}$ \\
\hline$\eta_{P}$ & Pumping efficiency & 0.8 & \\
\hline
\end{tabular}

\section{Results}

Results from the study are presented below.

\subsection{Smart thermal loop operation}

In Fig. 4, two separate weeks of STL operation - respectively, for the cooling and the heating season - are visualised as system temperatures and heat fluxes exchanged. In response to the thermal demand from the users, rHP are operated during the typical working hours (results from Fig. 4 refer to a case with no TES). As a consequence, the temperature in the UL departs from the neutral value and temperature differences drive the operation of the individual STL subsystems.

In cooling mode, heat is mainly rejected from the users and the UL operates as a sink. Temperatures increase along the loop, resulting in a positive $\Delta T$ and heat transfer to the BHE field $\left(Q^{B H E}\right)$. In this process, thermal inertia from the soil causes spikes to be lower and delayed in time, and UL-BHE heat exchange still happening after rHP are switched off (for about 2 to 5 hours). Thermal equilibrium is finally achieved, but at a higher temperature than the $15{ }^{\circ} \mathrm{C}$ undisturbed value. While providing heating, STL operation is reversed: UL now acts as a low-temperature source to supply users' demand and its temperature decreases. This allows heat to be transferred back to the UL from the BHE field, which is now at a higher temperature than the fluid. Also in this case, heat is exchanged between BHE and UL as long as a sufficient $\Delta T$ is present, even when rHP stops. 

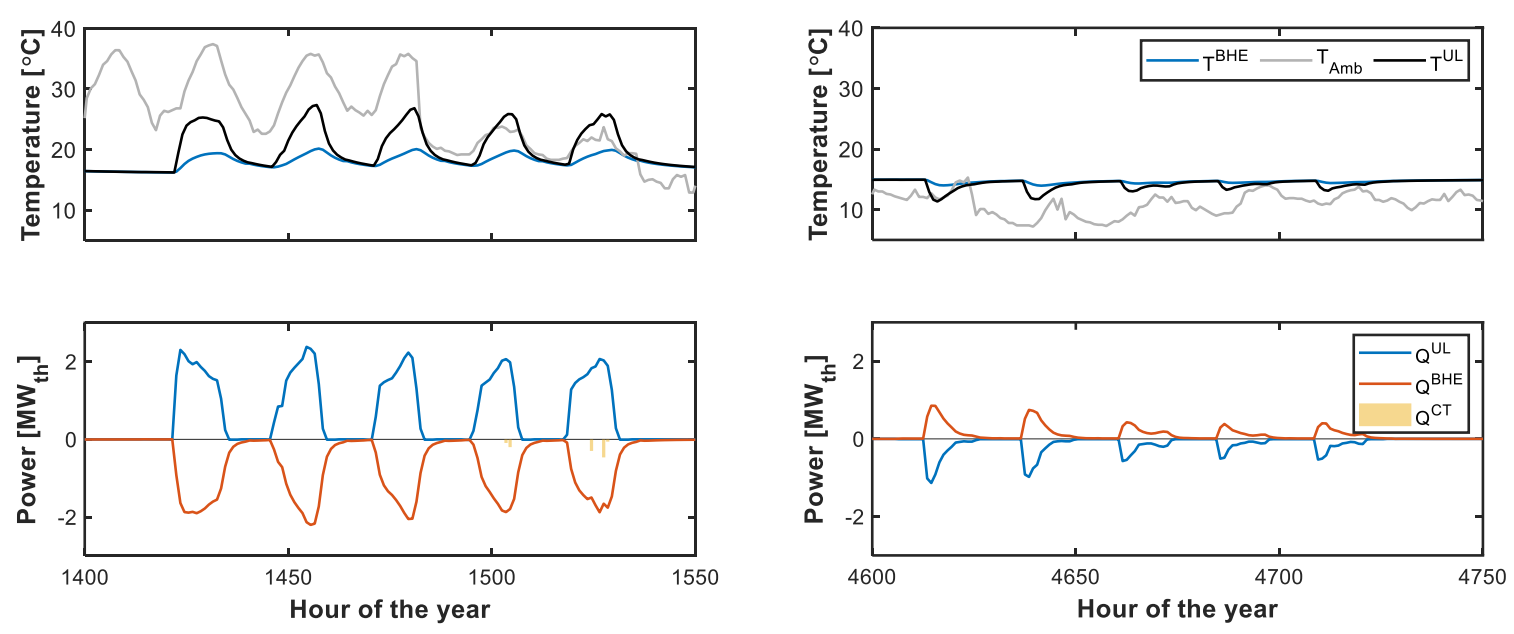

Fig. 4. 1-week STL operation during cooling season (left) and heating season (right)

When the ambient temperature is lower than UL values, the cooling tower can help lower the temperatures in the loop. However, CT is operated only a few times in the cooling week considered, because the benefit from lower UL temperatures must be traded with additional pumping work at the CT. Given the load patterns, STL displays a daily operation pattern. The heat stored in the UL follows daily swings, although in periods with repeated large heating and cooling demand, $T^{U L}$ at $24: 00$ varies from 14.4 to $18.6^{\circ} \mathrm{C}$ in our analysis. Overnight periods and weekends help re-establishing thermal equilibrium and avoid temperature build-up in the UL.

STL operation is beneficial when compared to a traditional system with local generation of heating and cooling. Yearly energy expenditure is $399 \mathrm{MWh}_{\mathrm{e}}$ in the case without TES, to be compared with $511 \mathrm{MWh}_{\mathrm{e}}$ if air-water heat pumps and chillers with COP and EER of 3 and 4, respectively, were to be used. This amounts to a $-22 \%$ on system operational costs and an analogous reduction in the associated $\mathrm{CO}_{2}$ emissions - possibly even higher, should heating be provided via gas boilers, instead - which represents one of the added values of $5 \mathrm{GDHC}$ networks compared to alternative systems. Through suitable use of short- and long-term TES, such operational and environmental benefits can further be enhanced, as discussed in the next sections.

\subsection{The role of thermal energy storage}

The attention is now focussed on exploring TES operation within the STL and understanding the added value it can bring to a low temperature network such as STL. Fig. 5 shows the yearly charge/discharge pattern for TES in a system with seasonal storage BHE field and 1-hour peak power capacity for the hot and cold TES. Hot and cold TES usage is associated with the demand (cooling concentrated in the summer months and heating throughout). It shows how short-time TES operates according to daily cycles, while the BHE field has a markedly seasonal behaviour, with heat mainly stored (positive values of power exchanged) in summer periods and retrieved during winter. Additionally, while hot and cold TES are charged and discharged evenly, there is an imbalance in the heat exchange with the BHE field: it is mainly stored. This is linked with the prevailing cooling load and further discussed later.
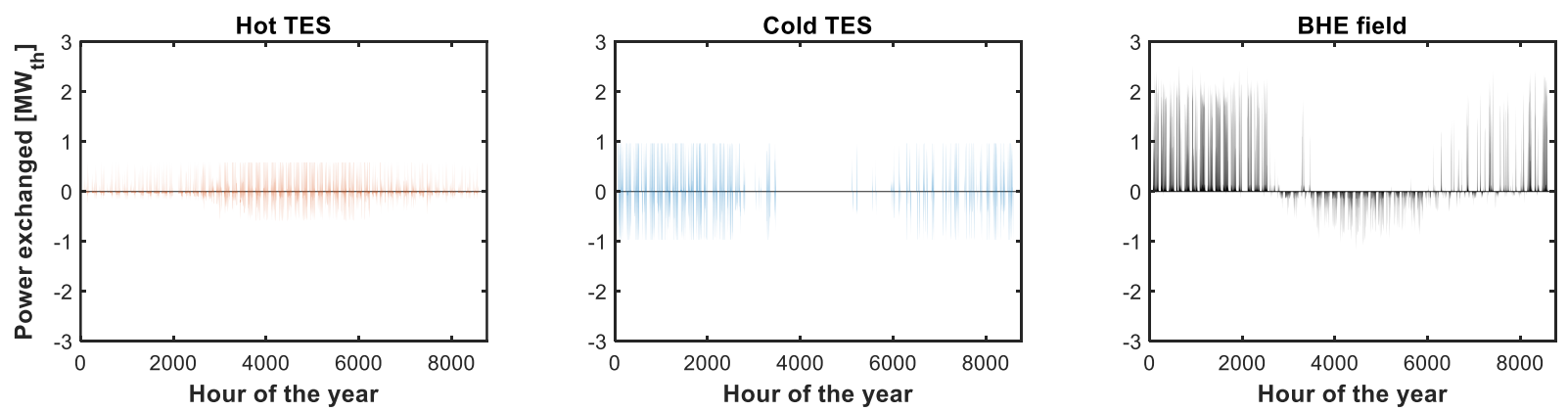

Fig. 5. Yearly charge/discharge pattern of short- and long-term TES in the investigated STL system.

\subsubsection{Impact of short-term TES}

The effect of short-term TES is investigated from the perspective of the STL operator in Fig. 6, where the assessment metrics are i) the energy import from the grid and ii) the system operating cost (OPEX), for different installed TES storage capacities. Compared with the case with no TES, a $1 \mathrm{~h}$ TES allows to cut energy expenditures by $10 \%$ and operational costs by $28 \%$. The energy import from the rHP does not change. In fact, 
it increases slightly due to the additional heat losses introduced by the TES. Pumping work decreases as it benefits from the scheduling flexibility and the reduced periods over which the system is operated (more concentrated delivery at higher outputs). Pumping represents a substantial portion of the STL yearly expenditure, and through the use of TES, its weight can be lowered from $26-27 \%$ to about $19 \%$, both in terms of energy and costs.

The impact of TES on system OPEX is much higher because it allows exploiting energy price differentials: a more efficient rHP scheduling can be achieved, to privilege operation in periods of low electricity demand and consequent low electricity price. This aspect is exemplified in Table 3 and brings considerable advantage to the energy system operator by an overall reduction of thermal peak loads and more even electricity demand. It is a benefit from heating and cooling electrification that is made accessible only thanks to the flexibility of short-term TES.
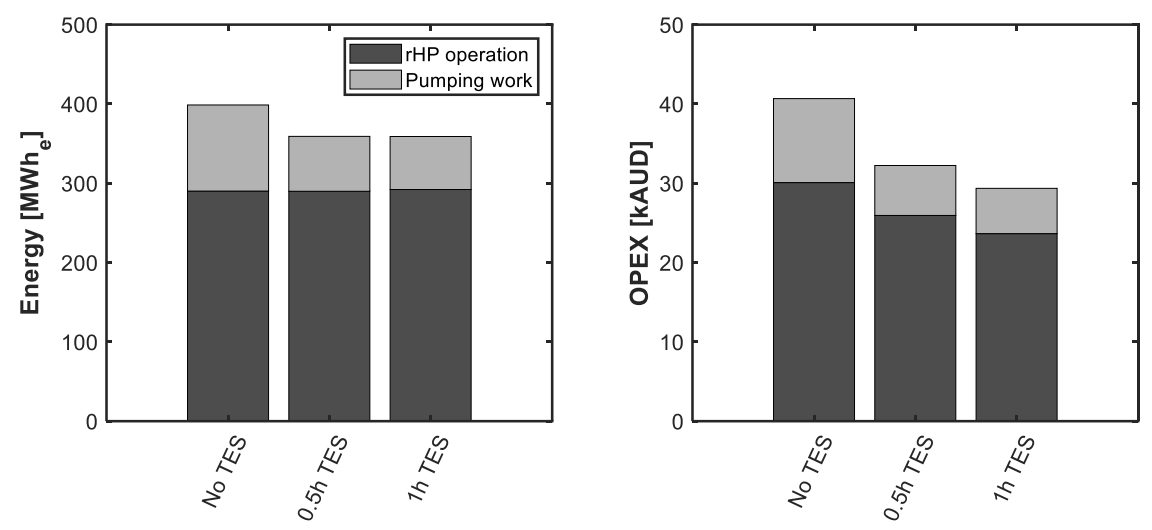

Fig. 6. Effect of different TES sizes on STL operational cost and energy import.

Besides an economically favourable scheduling, benefits from TES go beyond price arbitrage. The simulation tool developed allows quantifying such added value in terms of the yearly distribution of EER and COP coefficients from the rHP, which is shown in Fig. 7. The seasonal value changes from 4.81 to 4.60 for COP and 7.40 to 7.51 for EER. This has to be attributed to a technically favourable scheduling. As also shown in Table 3, heating is supplied by running the rHP for few hours at a higher setpoint, while the contrary happens for cooling, which is supplied at a slightly higher rHP setpoint. This scheduling allows the containment of temperature swings in the UL. Without TES, values for the UL oscillate between 10.4 and $30.9^{\circ} \mathrm{C}$, whereas in the case with TES, these become 9.8 and $27.4^{\circ} \mathrm{C}$. Operation at lower UL temperatures privileges EER over a minor decrease in COP and given the system is cooling-dominated, the optimisation goes this direction.
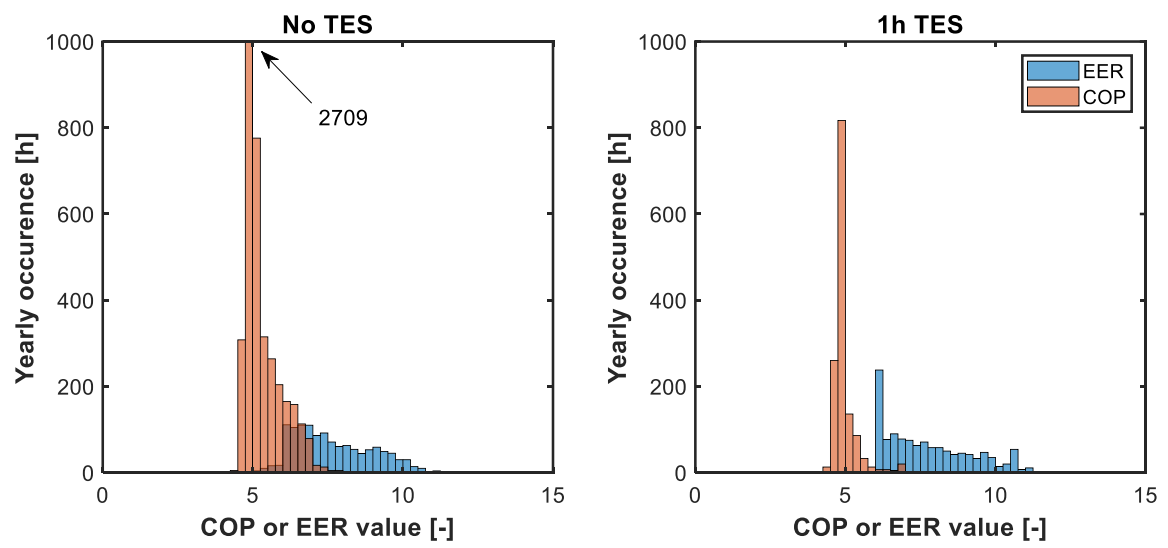

Fig. 7. Reversible heat pump COP and EER pattern for one-year STL operation; with and without TES.

Our analysis suggests that operation with fewer, yet more severe periods of reduced COP can economically outweigh the technical performance detriment if price arbitrage opportunities are available. This stresses the value of considering the techno-economics of STL as opposed to a purely technical or economic assessment. Conversely, cooling load is mostly concentrated during the central part of the day, when electricity prices are more stable, and similar operational changes do not apply. With 1-hour peak TES capacity, the STL energy expenditure can be $30 \%$ less than that for the reference traditional system with local generation of heating and cooling through air-water heat pumps/chillers. 
Table 3. Scheduling parameters for reversible heat pump and cooling tower, for different TES capacities.

\begin{tabular}{llll}
\hline Parameters & No TES & 0.5h TES & 1h TES \\
\hline Number of heating hours [h] & 5140 & 1737 & 1397 \\
Average heating output [kW] & 96 & 295 & 372 \\
Average heating switched-on period [hh:mm] & $2: 25$ & $1: 26$ & $1: 18$ \\
Number of cooling hours [h] & 1252 & 1380 & 1212 \\
Average cooling output [kW] & 1108 & 1022 & 1179 \\
Average cooling switched-on period [hh:mm] & $1: 59$ & 3.01 & $2: 37$ \\
Number of CT operating hours [h] & 157 & 153 & 194 \\
Average CT output [kW] & -401 & -473 & -482 \\
Average CT switched-on period [hh:mm] & $1: 39$ & $1: 40$ & $1: 40$ \\
\hline
\end{tabular}

\subsubsection{Impact of long-term TES}

The BHE field acts as long-term storage in the STL system investigated and it is charged/discharged based on the positive/negative temperature difference between the UL and the soil. This operation has the effect of containing the UL temperature deviations from the neutral value and ensures high performance values for $\mathrm{rHP}$. A markedly seasonal behaviour can be observed from Fig. 8, where the hourly and weekly average of the UL temperature, as well as the energy globally stored in the BHE field are reported, over one year. For most of the time, STL operates in the temperature range $10-20^{\circ} \mathrm{C}$, but temperature swings can reach $9.8^{\circ} \mathrm{C}$ in winter and $27.4{ }^{\circ} \mathrm{C}$ in summer, corresponding to a 5.2 and $12.4^{\circ} \mathrm{C}$ deviation from design conditions, respectively. Seasonal TES sizing has a chief role in containing such deviations (guidelines from ASHRAE [27] indicate acceptable values of $5-8^{\circ} \mathrm{C}$ for heating and $11-17^{\circ} \mathrm{C}$ for cooling).
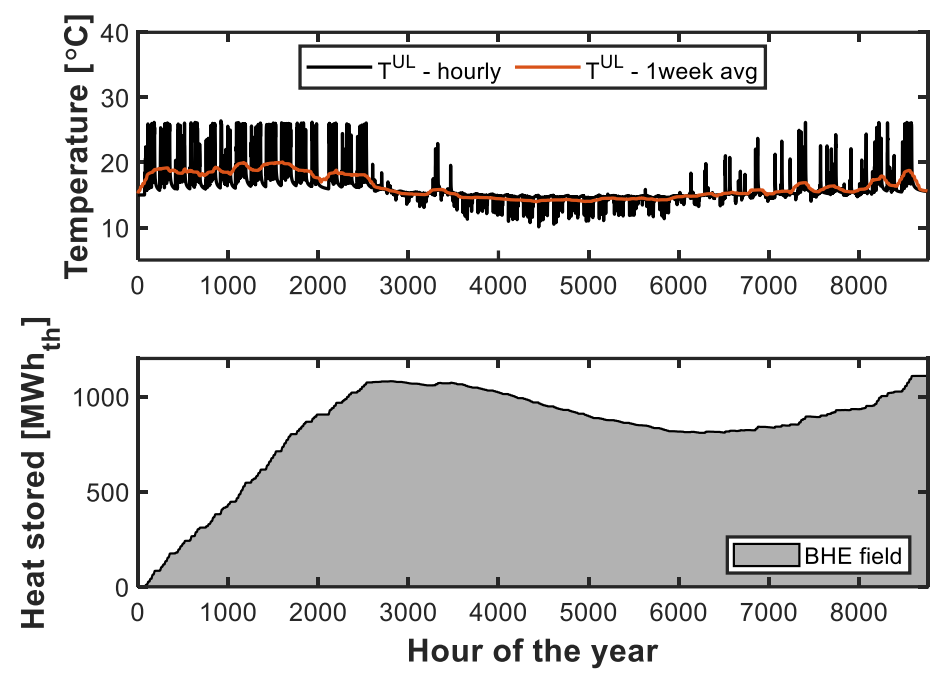

Fig. 8. One-year UL temperature evolution and cumulative heat stored in the BHE field.

The direct impact of temperature evolution in the UL can be seen in rHP performance. In fact, rHP can operate in the cooling season at higher EER values when the seasonal storage acts effectively as a thermal sink. Winter operation in heating mode is also performed at higher efficiency, while a limited portion of the total heat delivery which is required in the cooling season takes place at lower values of COP. Seasonal rHP performance values highlight this. COP is essentially stable at 4.60 , while EER increases from 6.90 to 7.51 , moving from 200 to $400 \mathrm{BHE}$, respectively. Hence, for the cooling-dominated system investigated, energy expenditure diminishes for larger BHE field. The same effect is registered for the energy import and the system OPEX (see Fig. 9) which shows BHE filed has only minor effect on STL scheduling. The pumping work contribution due to fluid circulation in the BHE field increases from 4.7 to $6.1 \mathrm{MWh}_{\mathrm{e}}$ when the number of BHE is increased from 200 to 400 , but this is more than offset by shorter periods of UL operation for rejecting/retrieving energy to/from the seasonal storage, and the overall pumping work is 84 and $60 \mathrm{MWh}_{\mathrm{e}}$, respectively, for 200 and $400 \mathrm{BHE}$. 

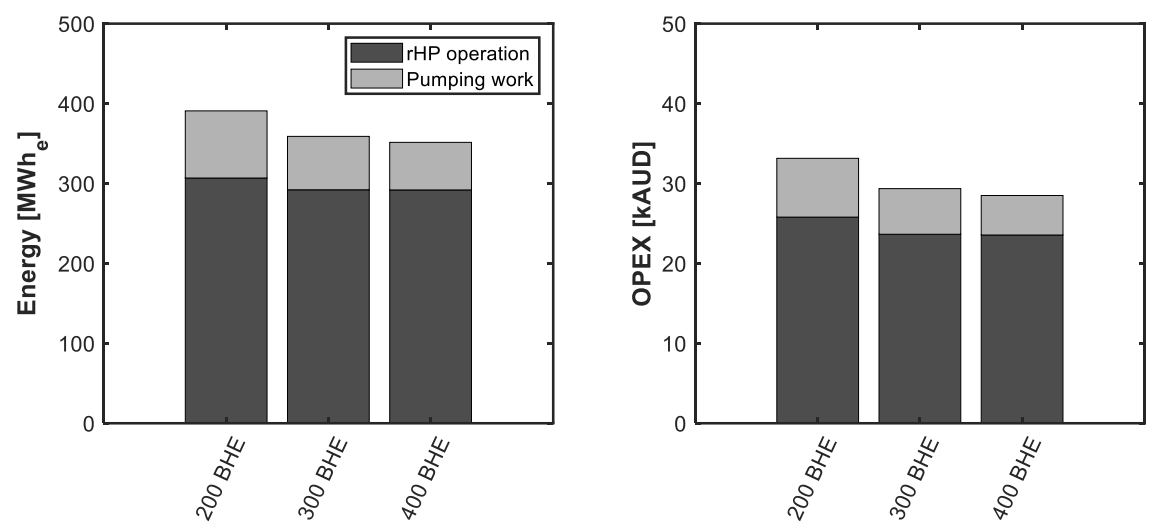

Fig. 9. Effect of different numbers of BHE on STL operational cost and energy import.

Different BHE field design affects the temperature dynamics and the heat transfer in the system, as shown in Fig. 10 for one-week STL operation. Higher heat fluxes can be exchanged between UL and the long-term TES for the same $\Delta T$, in case of more BHEs, leading to faster temperature dynamics and overall lower periods of temperature imbalance with the UL. The maximum temperature difference between UL and the geothermal field is 9.6 and $7.1^{\circ} \mathrm{C}$, in the two cases. This translates in a higher yield for a smaller geothermal field: effective heat transfer values registered throughout the year are up to $111 \mathrm{~W} / \mathrm{m}$ for 200 BHEs and $53 \mathrm{~W} / \mathrm{m}$ for 400 . In absolute terms, a maximum of $3.3 \mathrm{MW}_{\text {th }}$ is exchanged between $\mathrm{UL}$ and the geothermal field for $200 \mathrm{BHEs}$, and 3.2 $\mathrm{MW}_{\text {th }}$ for $400 \mathrm{BHEs}$. This denotes a nonlinear dependence between the number of geothermal probes and the field performance and suggests caution in the use of static BHE yield values for system design.
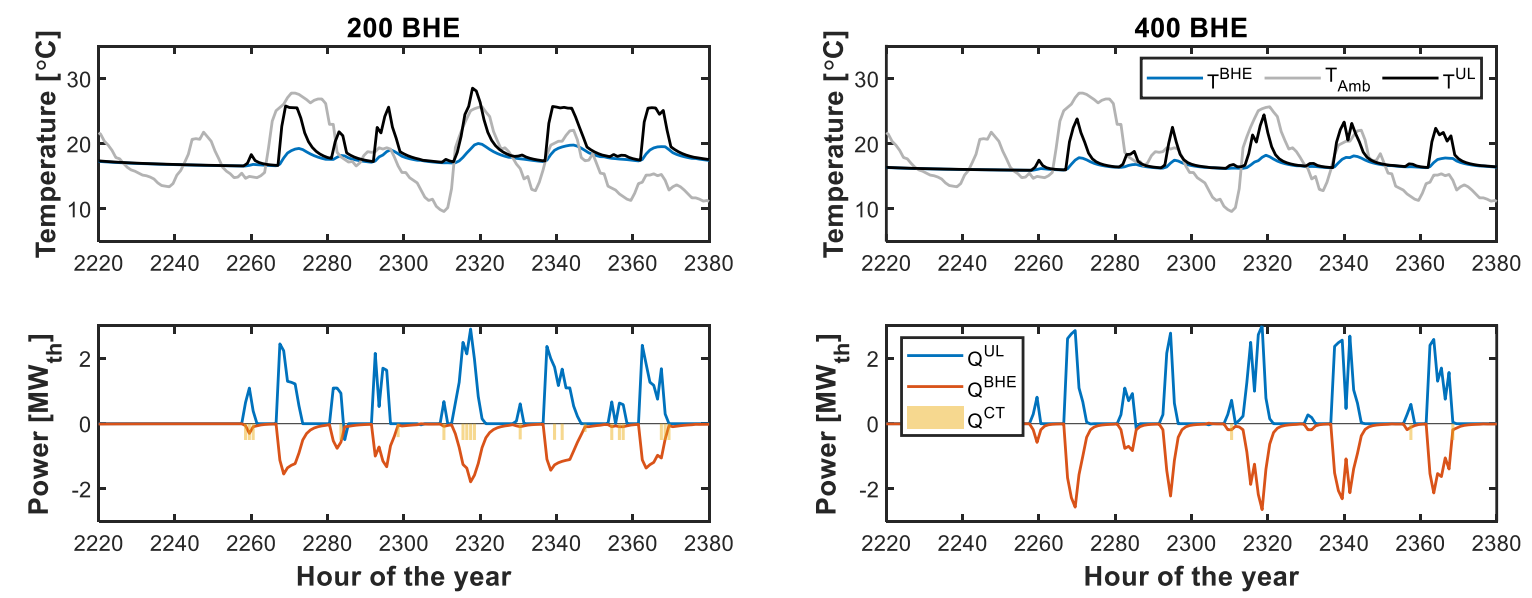

Fig. 10. Temperature and heat exchange in the STL, for different values of BHE in the seasonal TES.

Besides deviations in the thermal exchange between UL and the BHE, also heat rejection from the CT is affected by the design of the BHE field, as shown Table 4. In terms of energy, the BHE field absorbs 1471 and retrieves $320 \mathrm{MWh}_{\text {th }}$ throughout the year with $400 \mathrm{BHE}$, resulting in a final energy stored of $1151 \mathrm{MWh}_{\text {th. }}$ With $200 \mathrm{BHE}, 1279 \mathrm{MWh}_{\text {th }}$ are absorbed and 314 retrieved, for $965 \mathrm{MWh}_{\text {th }}$ of net energy storage. Therefore, a larger BHE field allows rejecting towards the ground a bigger portion of the yearly load imbalance, in a coolingdominated location, which results in a final temperature at the end of the simulation being closer to the neutral value of $15^{\circ} \mathrm{C}$. Therefore, a higher number of BHE is beneficial for STL performance; space constraints of the installation and thermal interference between individual probes in the long term constitute the main considerations restricting the design choice.

Table 4. Selected STL operational parameters for different number of BHE.

\begin{tabular}{llll}
\hline Parameter & 200 BHE & 300 BHE & 400 BHE \\
\hline Maximum UL temperature $\left[{ }^{\circ} \mathrm{C}\right]$ & 40.8 & 27.4 & 27.2 \\
Mean UL temperature $\left[{ }^{\circ} \mathrm{C}\right]$ & 16.6 & 16.2 & 16.0 \\
Minimum UL temperature $\left[{ }^{\circ} \mathrm{C}\right]$ & 9.2 & 9.8 & 10.9 \\
Final UL temperature $\left[{ }^{\circ} \mathrm{C}\right]$ & 15.7 & 15.5 & 15.4 \\
Yearly CT thermal energy transfer $[\mathrm{MWh}]$ & -254 & -94 & -51
\end{tabular}




\begin{tabular}{llll} 
Yearly BHE thermal energy transfer [MWh] & -965 & -1108 & -1151 \\
Maximum $Q^{C T}[\mathrm{MW}]$ & 0.9 & 1.2 & 1.2 \\
Minimum $Q^{B H E}[\mathrm{MW}]$ & -3.3 & -2.5 & -3.2 \\
Maximum BHE field yield $[\mathrm{W} / \mathrm{m}]$ & 110.7 & 56.4 & 53.0 \\
\hline
\end{tabular}

\section{Conclusions}

In the present study, a MILP model for the considered 5GDHC network is developed and used to simulate the operation for the new UoM campus located in Melbourne, Australia. Outcomes confirm 5GDHC networks operation is driven by temperatures. $\Delta T$ develop across the system in consequence of rHP operation, acting as the driving force for heat to be stored and retrieved to/from the BHE field or rejected from the CT towards the environment. So, it is important to carefully track network temperature evolution over time and capture the performance dependence of system devices to properly simulate system behaviour. Key results on the effect of different sizes of short- and long-term TES in determining efficient techno-economic system operation can be summarised as follows:

- Short-term TES: it primarily balances daily loads, positively impacting not only on system profitability but also on components performance such as COP and EER for the rHP. Electrification benefits and technically favourable scheduling can only be unlocked through the flexibility short term TES offers. In the investigated case, $1 \mathrm{~h}$ peak capacity TES reduces system running costs by $28 \%$, through $10 \%$ lower energy import, seasonal EER improvement from 7.40 to 7.51 of rHP and flexible scheduling.

- Long-term TES: it balances seasonal load variations and contains temperature fluctuations in the network. For balanced heating and cooling load, the energy charged and discharged should balance each one out, on a yearly basis. In a cooling-dominated integration such as the investigated UoM campus, in Melbourne, about 4 times more heat is rejected than retrieved. For a careful system design, multi-year simulations are necessary.

Results can inform on the role that TES plays in enabling flexible operation, not only in the present study, but more broadly, for $5 \mathrm{GDHC}$ networks. Also, when complemented by cost-benefit analysis, results can assist the optimal short- and long-term TES design, and contribute to 5GDHC network uptake in the Australian context.

\section{Acknowledgments}

Andrea Vecchi acknowledges the Priestley Joint PhD Scholarship from University of Birmingham (UK) and University of Melbourne (Australia)

\section{Nomenclature}

\section{Sets}

$i \quad$ set of rHP, from 1 to $I$

$j \quad$ set of TES, from 1 to $J$

$n \quad$ set of UL nodes, from 1 to $N$

$t \quad$ set of times, form 1 to $T$

$s \quad$ set of COP and EER discretisation intervals, from $s$ to $S$

\section{Optimisation variables}

$\boldsymbol{P} \quad$ electric power, $\mathrm{kW}$

$\boldsymbol{Q}$ thermal power, kW

SoC TES state of charge, $[\mathrm{kWh}]$

$\boldsymbol{T}$ temperature, ${ }^{\circ} \mathrm{C}$ $\boldsymbol{u}$ COP/EER discretisation interval binary indicator

$y \quad$ on/off binary indicator

$z \quad$ rHP heating mode binary indicator

\section{Subscripts and superscripts}

BHE borehole heat exchanger

C cooling

CT cooling tower

$\mathrm{H} \quad$ heating

$P \quad$ pumping

TES thermal energy storage

UL underground loop

rHP reversible heat pump

\section{References}

[1] Ürge-Vorsatz D, Cabeza LF, Serrano S, Barreneche C, Petrichenko K. Heating and cooling energy trends and drivers in buildings. Renew Sustain Energy Rev 2015;41:85-98. doi:10.1016/j.rser.2014.08.039.

[2] Isaac M, van Vuuren DP. Modeling global residential sector energy demand for heating and air conditioning in the context of climate change. Energy Policy 2009;37:507-21. 
[3] Departemen of Economic and Social Affairs United Nation. World Urbanization Prospects 2018. 2018.

[4] Rismanchi B. District energy network (DEN), current global status and future development. Renew Sustain Energy Rev 2017;75:571-9. doi:10.1016/j.rser.2016.11.025.

[5] Lund H, Werner S, Wiltshire R, Svendsen S, Thorsen JE, Hvelplund F, et al. 4th Generation District Heating (4GDH) Integrating smart thermal grids into future sustainable energy systems. Energy 2014;68:1-11. doi:10.1016/j.energy.2014.02.089.

[6] Buffa S, Cozzini M, D'antoni M, Baratieri M, Fedrizzi R. 5th generation district heating and cooling systems: A review of existing cases in Europe 2019. doi:10.1016/j.rser.2018.12.059.

[7] Schmidt D, Kallert A, BlesI M, Svendsen S, Li H, Nord N, et al. Low Temperature District Heating for Future Energy Systems. Energy Procedia, vol. 116, Elsevier Ltd; 2017, p. 26-38. doi:10.1016/j.egypro.2017.05.052.

[8] Østergaard D, Svendsen S. Space heating with ultra-low-temperature district heating - A case study of four single-family houses from the 1980s. Energy Procedia, vol. 116, Elsevier Ltd; 2017, p. 226-35. doi:10.1016/j.egypro.2017.05.070.

[9] Lund H, Østergaard PA, Nielsen TB, Werner S, Thorsen JE, Gudmundsson O, et al. Perspectives on fourth and fifth generation district heating. Energy 2021;227. doi:10.1016/j.energy.2021.120520.

[10] Sarbu I, Sebarchievici C. General review of ground-source heat pump systems for heating and cooling of buildings. Energy Build 2014;70:441-54. doi:10.1016/j.enbuild.2013.11.068.

[11] Shah SK, Aye L, Rismanchi B. Multi-objective optimisation of a seasonal solar thermal energy storage system for space heating in cold climate. Appl Energy 2020;268. doi:10.1016/j.apenergy.2020.115047.

[12] Vandermeulen A, Van Der Heijde B, Helsen L. Controlling district heating and cooling networks to unlock flexibility: A review 2018. doi:10.1016/j.energy.2018.03.034.

[13] Bünning F, Wetter M, Fuchs M, Müller D. Bidirectional low temperature district energy systems with agent-based control: Performance comparison and operation optimization. Appl Energy 2018:502-15. doi:10.1016/j.apenergy.2017.10.072.

[14] Buffa S, Soppelsa A, Pipiciello M, Henze G, Fedrizzi R. Fifth-Generation District Heating and Cooling Substations: Demand Response with Artificial Neural Network-Based Model Predictive Control n.d. doi:10.3390/en13174339.

[15] Wirtz M, Kivilip L, Remmen P, Müller D. 5th Generation District Heating: A novel design approach based on mathematical optimization 2019. doi:10.1016/j.apenergy.2019.114158.

[16] Gabrielli P, Acquilino A, Siri S, Bracco S, Sansavini G, Mazzotti M. Optimization of low-carbon multienergy systems with seasonal geothermal energy storage: The Anergy Grid of ETH Zurich. Energy Convers Manag X 2020:100052. doi:10.1016/j.ecmx.2020.100052.

[17] Sommer T, Sulzer M, Wetter M, Sotnikov A, Mennel S, Stettler C. The reservoir network: A new network topology for district heating and cooling 2020. doi:10.1016/j.energy.2020.117418.

[18] Prasanna A, Dorer V, Ege Vetterli N. Optimisation of a district energy system with a low temperature network 2017. doi:10.1016/j.energy.2017.03.137.

[19] Revesz A, Jones P, Dunham C, Davies G, Marques C, Matabuena R, et al. Developing novel 5th generation district energy networks 2020. doi:10.1016/j.energy.2020.117389.

[20] Incropera FP, DeWitt DP, Bergman TL, Lavine AS. Introduction to heat transfer. 2006.

[21] Bandos T V, Montero Á, Fernández E, Luis Santander JG, María Isidro J, Pérez J, et al. Finite linesource model for borehole heat exchangers: effect of vertical temperature variations. Geothermics 2009;38:263-70. doi:10.1016/j.geothermics.2009.01.003.

[22] Miglani S, Orehounig K, Carmeliet J. Integrating a thermal model of ground source heat pumps and solar regeneration within building energy system optimization 2018. doi:10.1016/j.apenergy.2018.02.173.

[23] Lamarche L, Beauchamp B. A new contribution to the finite line-source model for geothermal boreholes n.d. doi:10.1016/j.enbuild.2006.06.003.

[24] Hackel S, Nellis G, Klein S. Optimization of hybrid geothermal heat pump systems. 9th Int IEA Heat Pump Conf 2008:20-2.

[25] Rees S. Advances in ground-source heat pump systems. Woodhead Publishing; 2016.

[26] Viessmann. Heat pumps up to $2000 \mathrm{~kW}$ : Vitocal pro. Technol Broch 2000.

[27] Kavanaugh SP, Rafferty KD. Geothermal Heating and Cooling: Design of Ground-source Heat Pump Systems. ASHRAE; 2014. 


\section{University Library}

\section{- M M I N E R VA \\ A gateway to Melbourne's research publications}

Minerva Access is the Institutional Repository of The University of Melbourne

Author/s:

Vecchi, A;Rismanchi, B;Mancarella, P;Sciacovelli, A

Title:

Daily and seasonal thermal energy storage for enhanced flexible operation of lowtemperature heating and cooling network

Date:

2021

Citation:

Vecchi, A., Rismanchi, B., Mancarella, P. \& Sciacovelli, A. (2021). Daily and seasonal thermal energy storage for enhanced flexible operation of low-temperature heating and cooling network. Ecos 2021 \#, Ecos 2021 \#. https://doi.org/10.52202/062738-0047.

Persistent Link:

http://hdl.handle.net/11343/281896

License:

Unknown 